\title{
The Contribution of Advocacy NGOs in Governance through Cultivating of a Participatory Culture: Case Studies in Hong Kong
}

\author{
Yui Kei LEUNG*, Yan Wing LEUNG, Timothy Wai Wa YUEN \\ Department of Education Policy and Leadership, The Hong Kong Institute of Education, China
}

Copyright $(2016$ by authors, all rights reserved. Authors agree that this article remains permanently open access under the terms of the Creative Commons Attribution License 4.0 International License

\begin{abstract}
A vibrant civil society, composed of active non-governmental organizations (NGOs), has always been identified as an important factor for "good governance". This paper reports a pilot study using semi-structured interviews to find out the contribution of advocacy NGOs in the governance of Hong Kong. It points out that the NGO's conception of good governance in the Hong Kong context, as revealed by the findings, comprises inter alia: legitimacy obtained through democratic elections, ability to realize the autonomy of the HKSAR, and proper checks and balances not just within the government but also about the possible domination of business interest in the government's policy making process. It further reveals how NGOs can contribute to "good governance" by nurturing a democratic culture through civic education in schools. Hopefully this paper can be of reference value to the international audience as it reflects how the worldwide criteria of good governance are reflected in the context of Hong Kong, a special administrative region with a high degree of autonomy where the building up of a truly democratic government is yet to be realized.
\end{abstract}

Keywords Non-governmental Organizations (NGOs) Advocacy Groups, Good Governance, Citizenship Education, Autonomy, Democratic Government, Political Arena

\section{Introduction}

In the $21^{\text {st }}$ century, there has been worldwide recognition that without active citizenship, which comprises both voting and active participation in civil society, democratic governance is fragile. In a modern society, many actors are involved in governance. Whilst government is certainly the major actor, various roles in civil society, particularly those related to enhancing active citizen participation are indispensable, These roles are played by mass media, multi-national corporations, NGOs, research institutes, religious leaders, finance institutions and political parties... etc. are nonetheless important. While 'poor governance' is being increasingly considered as one of the root ingrained problems of most evils in our societies, principles, indicators or criteria of 'good governance' have also been identified.

In Hong Kong, many advocacy NGOs are getting more involved in the process of cultivation of a participatory culture through civic education in the communities and by partnering with civic educators in schools. This paper reports part of the initial findings of an exploratory case study based on interviews with the leaders of seven local advocacy NGOs. It explores (1) how the NGOs understand governance and good governance, (2) in what way they perceive themselves as contributing to good governance through shaping of participatory political culture. The paper starts with a brief review of literature on the meanings of governance, characteristics of good governance, meanings of civil society, and the relationship between civil society and governance. This is followed by a brief discussion of the Hong Kong context and the civil society in Hong Kong. The initial findings of the study will then be discussed, revealing the NGOs' understanding of good governance, which are manifested through their comments on the Hong Kong government, alongside with how the NGOs can contribute to 'good governance' through citizenship education in shaping a participatory culture. Given the limitations of case studies, particularly in the ability to make generalization, it is hoped that the findings of the paper could add values to the literature and policy formulation related to the relationship between governance and NGOs, both locally and internationally.

\section{Governance}

The traditional use of the word 'governance' and its dictionary entry usually define it as a synonym for 
'government', referring to "the formal and institutional processes which operate at the level of the nation state to maintain public order and facilitate collective action" $[1$, p.17]. Moreover, there is a shift towards understanding the term as governance style in which boundaries between public and private sectors have become blurred [1]. This shift has a focus on governance mechanisms which do not rely on the recourse to the authority and sanctions of government, but on the interaction of a multiplicity of governing and each other influencing actors [2]. It is a shift from a unilateral (government or society separately) to an interactionist focus (government with society), with a growing realization of inter-dependencies [3]. Literature also argues that whilst traditional concept of governance is more top down and focused on the delivery of 'political good' to the citizens by the government, which is state-centred, contemporary re-conceptualization of the idea of governance gives equal importance to the governability of society. Society is conceived not just as the target of administration or governance, but a conglomeration of self-governing capacities of segments of society, or of self-regulating and autonomous 'networks', which may be considered as characteristics of civil society. This implies the necessity for a genuine autonomous civil society that agrees on certain basic institutions and shared values, such as freedom, democracy, tolerance, justice, rule of law, human rights, participation, trust etc. [4].

\section{Characteristics of Good Governance}

Recent literature on governance has highlighted that 'poor governance' is being increasingly considered as one of the root problems of most evils in our societies. In identifying what 'good governance' is, various sets of principles, indicators or criteria of 'good governance' have been proposed. For example, the Worldwide Governance Indicators (WGI) project [5] suggests six dimensions of governance as indicators: Voice and Accountability, Political Stability and Absence of Violence, Government Effectiveness, Regulatory Quality, Rule of Law and Control of Corruption. The European Governance White paper [6] proposed five principles of good governance, namely, Openness, Participation, Accountability, Effectiveness and Coherence. UNESCAP [7] proposes eight characteristics, namely Participatory, Consensus Oriented, Accountable, Transparent, Responsive, Effective and Efficient, Equitable and Inclusive and Follows the Rule of Law. Though they may have different emphasis according to the context, they all share the most important common features of interactionist focus between the government and civil society and require the active participation of citizens. Nonetheless, the characteristics of good governance discussed focus mainly on the system, institutional and process factors. The human factor is being ignored. However, as revealed in our findings human factors are also vital. Therefore, the present research will also investigate good governance from this perspective.

\section{Civil Society and Good Governance}

The importance of civil society in maintaining and promoting good governance and poverty reduction locally, nationally and globally, is being increasingly recognized [6,8-9]. Edwards [10, p.125] argued forcefully that 'against the background of weak democracies, strong bureaucracies, corporate power, legalism and nationalism resurgent, civil society is essential to the prospects for a peaceful and prosperous world order in the twenty-first century, because it "leads us to a renewed awareness of the fusion of the moral, the social and the political in the constitution of all human communities [11, p.3]" "As discussed above, active citizens and vivacious civil society have always been included as an important aspect of the principles, indicators or criteria of 'good governance'. The organizations that make up civil society ${ }^{1}$ mobilize and support those who are marginalized and excluded. Some of the organizations are actively involved in defending or promoting specific causes and seeking to influence the related public policies and practices, while some of them are actively involved in nurturing the citizens' civic awareness. Some organizations may use an indirect and rather passive approach, e.g. through the mass media, to influence the development of 'good governance' [6].

Similar to 'governance', the term 'civil society' has a variety of meanings, though there is an emerging consensus on its key characteristics. Edwards [10] summarized the concepts of civil society as (1) an associated life, (2) the good society and (3) the public sphere. He argued that "theories of the good society help to keep our gaze on the goals and challenges that motivate the search for freedom and human progress; theories of associated life help to explain how to meet those challenges through the medium of non-state action, which is always necessary but never sufficient, and theories of the public sphere connect the two together by providing a framework for argument and negotiation around social goals and the strategies required to reach them " $[10$, p.124] and he argued for the necessity of all three. In this paper, the definition by [12, p.379], which is commonly used and manifests the three ideas of Edwards, is adopted as a working definition: "an intermediate associational realm between state and family, populated by organizations which are separated from the state, enjoy autonomy in relation to the state and are formed voluntarily by members of society to protect or extend their interests and values". This definition also reflects observers' key consent characteristics on civil society.

\section{The Hong Kong Context}

Historically, Hong Kong NGOs have been vital in the development of the community since it was ceded to Britain in 1842. In the early colonial period, they were active in the form of welfare associations, guilds, and religious 
organizations, which acted as the major welfare providers for the society. As Hong Kong started to become urbanized and industrialized in the 1970 s, the government put more resources into welfare and has become the major financial provider for education, health, housing and welfare. Nevertheless, the NGOs were regarded as partners in service provision, playing the role of providing direct service, while the government provided the resources. Hong Kong society became more politicized and more and more Hong Kong people began to be aware of their various political, civil, economic and cultural rights after 1997. This led to the emerging of many vocal NGOs championing and advocating for various issues ${ }^{2}$, such as human rights, minorities' rights, universal franchise, poverty, environmental and suitability issues and influencing related policies. Most of them also consider their role as educators, empowering citizens and stakeholders and some of them also provide direct service.

According to the Civil Society Index Report [13], Hong Kong civil society can be described as 'loose but vibrant' (p.vi). It reported that "it is loose because of the low level of structure as well as communication among CSOs. It is vibrant because it actively strives to respond to social needs and empower minority groups; and in the process, it enjoys various degrees of success in promoting certain social values" (p.vi, item 9). The report also highlighted the strength of Hong Kong civil society as "(1) enthusiasm in advocating ideas and values, (2) ability to shape public agenda and challenge public policy and (3) robustness in responding to societal needs and providing services" (p.v. item7). In addition, "civic education: the cultivation of an enabling socio-cultural environment for effective function of civil society" (p.vi, item 11) has been proposed as an important agenda for improving the functioning of civil society.

Thus, it is crystal clear that active participation of citizens is a crucial element in good governance. However, since Hong Kong has been a British colony for 150 years, Hong Kong citizens are apolitical, who usually only care about self-interest and their awareness of rights to participate in public policies is not high. Fairbrother [14] argued that even after 1997, Hong Kong basically remains a society with relatively strong civil and social rights but feeble political rights. Ghai [15] claimed that the Hong Kong Basic Law, the mini constitution for Hong Kong, has laid down a political structure with a restricted franchise, hindering the development of an active and participatory citizenship. Though there have been various kinds of school based civic education, their effect is still questionable [16]. Therefore, civic education, supported by NGOs, is much needed to supplement the school based effort for the cultivation of active citizenry for an enabling socio-cultural environment for effective function of civil society. Thus, in order to investigate the contribution of NGOs to governance in Hong Kong, first of all, it is essential to explore how the NGOs in Hong Kong understand what governance is and what the characteristics of good governance are. Secondly, as the active citizenry need to be strengthened, there is a need to explore how the NGOs perceive themselves as contributing to good governance through shaping of participatory political culture and acting as civic educator.

\section{Research Design}

According to NGO Handbook, the definition of "advocacy" is the act of arguing on behalf of a particular issue, idea or person. Individuals, organizations, businesses, and governments can engage in advocacy. For "advocacy organizations", the NGO Handbook says that they are organizations which endeavor to voice their message out to the public, governments and other interested parties to effect and impact policy change and political developments [17]. Non-governmental organizations played a very important role in shaping government policies in Hong Kong. They are one of the indispensable factors contributing to "good governance" in Hong Kong. NGOs may be charity organizations, civic groups, and social movement organization etc., each of which providing services to hundreds and thousands of needy people in Hong Kong daily. Generally speaking, they reflected people's interests in the vibrant civil society as well as catered for their needs. It is no doubt that NGOs are able to shape government policies directly through their support to the HKSAR Government's policies, and indirectly through their voicing of people's needs. As there are hundreds and thousands of NGOs in Hong Kong, for administration and research convenience, the researchers purposely classified NGOs in Hong Kong into 3 categories, namely, Radical, Moderate and Conservative categories according to their beliefs and whether they are supporting government policies. The researchers understand that within limited resources and time, it is difficult if not impossible to conduct a full-fledged research on all NGOs in Hong Kong. Thus, the researchers deemed it necessary to focus the present research on the advocacy NGOs, i.e. NGOs which endeavor to voice their message out to the public, governments and other interested parties to effect and impact policy change and political developments, and hoping that the research could shed some light on the contribution of advocacy NGOs to "good governance" in Hong Kong. The researchers then randomly invited leaders of 7 NGOs in Hong Kong (with 2 from each of the above-mentioned Radical and Conservative categories and 3 from the moderate category), to participate in the semi-structured interviews. These NGO leaders spoke on behalf of their NGOs with regarded to NGOs' views on "good governance" and critically assessed their contribution to good governance of Hong Kong.

This paper is a report of part of the initial findings of an exploratory case study based on interviews with leaders of the seven local advocacy NGOs from the above-mentioned 3 categories, conducted from January 2011 to September, 2012. It intends to address the following two research questions: 
(1) How do the NGOs leaders understand governance and good governance?

(2) In what way(s) do they perceive themselves as contributing to good governance through shaping of participatory political culture and acting as civic educator? Sampling

The seven advocacy NGOs (A, B, R, S, X, Y, Z) which can be categorized into three types were purposively sampled. Three of them $(\mathrm{X}, \mathrm{Y}, \mathrm{Z})$ are more livelihood oriented, which focus on livelihood of the marginalized people. Fighting for social justice is a common concern for all three of them. NGO Z has a particular focus on those grass root people receiving the Comprehensive Social Security Assistant. In addition to livelihood of the marginalized people and issues related to social justice, NGOs X and Y have a broad concern about issues of human rights in general and universal franchise though NGOs has a very strong Christian orientation, they are always being regarded as Radicals. NGO A focuses mainly on the democratic development of Hong Kong and the political rights to universal franchise. NGO B concerns public policy in general and is more research oriented. Owing to their fact that these 2 NGOs are rather new in the political arena and their resources are limited, they are moderate in nature as compared with the other two categories. NGO R and NGO S are more like "think tanks" which as they are more research oriented and concern with public policy in general. NGO S associates with a political party and its leaders are also the leaders of the political party. These two are regarded as conservative as they are rather mild in their criticism on government policies. All of these NGOs received their funding from the private sector. They are not considered to be members of the pro-establishment NGOs and are supposed to be independent from the government. Thus, their responses could help the researchers to constitute an impartial evaluation on good governance and NGOs' contribution to good governance in Hong Kong.

\section{Collection of Data}

The data were collected mainly from interviews of the representatives from the NGOs. There were two representatives from NGO X and one from each of the rest. The representative/s of each NGO was/were interviewed once for about one hour to one and a half hours on the NGO's views on 'good governance' and NGOs' contribution to good governance with reference to shaping of participatory political culture and action as civic education in particular according to their understanding and interpretation. The number of staff within these 7 NGOs was difficult to calculate as some of them were voluntaries. Yet, the total number of staff full time for these 7 NGOs was more than 300. It is crystal clear that it is difficult to distinguish NGOs and the number of employees from the total number of organizations and working population within Hong Kong, especially there may be some part-time as well as voluntary workers. Within limited resources and time, the researchers thus limited the samples of interviewees to seven, albeit it was small, they represented more than $5 \%$ of the total working population of 4,900 within the Health Care and NGO services working population in Hong Kong [18]. Semi-structured interview guides were used to guide the interviews. The interviewees were free to pick up any topics they deem pertinent. All interviews were conducted in the dialect of the participants, taped, and transcribed verbatim. The interviews data were supplemented by data from documentary analysis of the websites of the NGOs.

\section{Data analysis}

For addressing research question 1, based on the literature, two themes, General Understandings of Governance and Characteristics of Good Governance, with sub-themes were developed for the analysis of the scripts.

For analysis of research question 1, they are:

(1) General understandings of governance

(2) Characteristics of good governance:

(a) Institutional Factors:

- Legitimacy and Power : source of legitimacy, autonomy, check and balance of power;

- Participation and involvement of civil society: rights to participation, mode of participation ;

- Accountability;

- Rule of Law;

- Transparency;

- Responsiveness;

- Consensus Oriented;

- Equity and Inclusiveness;

- Political Stability and Absence of Violence;

- Regulatory Quality

(b) People's Factors:

- Decision Makers

- Active Citizens

For analysis of research question 2, the following themes were derived from the data:

- NGO, Dialogues and Education: Community Dialogues (both with NGOs and people);

- Community Education;

- Views of Educational Policy for shaping Citizenship;

- Collaboration with Formal Education

In analyzing the qualitative data, the researchers adopted a method that shared some of the attributes Glaser and Strauss [19] described as 'constant comparative method'. In putting the scripts into different themes or sub-themes, each interview transcript was compared with another transcript, one incident with another incident. Though peer debriefing was not used in the analysis, the researchers shared the qualitative data they collected and made decisions together on such matters as coding, categories, and data saturation, etc. This helped to avoid excessive subjectivity in inference. It should be noted that there may be overlaps among the themes and sub-themes and the same scripts can also be classified under different themes or sub-themes. 


\section{Findings and Discussion}

Due to limited space, for research question 1, we shall focus on the General Understandings of Governance, and the Characteristics of Good Governance: Institutional Factors "Legitimacy and Power" and the sub-themes, which are vital to good governance of Hong Kong. The People's Factors and the sub-themes will also be discussed.

\section{General Understandings of Governance}

The general understanding of governance expressed by two of the NGO representatives were very similar to the recent literature, a broadened view including government, civil society, citizens and the interactions among them. Representative from NGO A said:

Governance is the whole process of public policy decision making and implementation. A good governance should involve listening, involving and taking seriously of people's voice in the decision makings and implementations.

Representative from NGO Y echoed similar views:

The government is very important in governance but it is not equivalent to governance. In my view, since people are the sovereignty, people should be part of the governance. Governance is a system that the government is mandated and legitimized by the people. It involves people in election and decision makings.

Representative from NGO R incorporated the same view into the ruler and ruled relationship:

Governance is a cycle. People voiced and put forward their opinions. Government gathered all opinions to formulate policies and then implemented them through relevant departments.

NGO S stressed accountability and transparency:

For good governance, the government must be accountable and maintain a close relationship with citizens; they must respond quickly to social issues. But most of all, I think accountability and transparency are most important- this means it would be impossible for the government to deal under the table or allow government-business collusion.

Characteristics of Good Governance: Institutional Factors

Overall speaking, the views about Hong Kong's governance expressed by the NGOs tended to be negative. They talked about Characteristics of Good Governance from their negative perceptions of Hong Kong's governance, generated from their experiences. This may be because they stayed close to the marginalized people and aloof from the establishment.

\section{Legitimacy and Power}

There are three sub-themes, including source of legitimacy, autonomy, and check and balance of power

\section{Source of Legitimacy}

The source of legitimacy which refers to the perceptions of the extent to which the people are able to participate in selecting their government is a very crucial characteristic of good governance identified in the literature. The interviewees considered it crucial:

First, I will ask why they have the power to rule. Why do Hong Kong people have to be ruled by them? Fundamentally, this is the issue of legitimacy of the government. This is basically an issue of democratic governance that we are fighting for (NGO Z).

The most fundamental issue is the issue of legitimacy because even for efficiency and effectiveness of policy implementation, at the end, it is the legitimacy that counts. The many conflicts and debates around the Chief Executive and Legislative Council of Hong Kong are due to the issue of legitimacy and mandate (NGO B).

My NGO has long been fighting for a democratic government elected by universal franchise of the people. The government should be built on the support and mandate of people. They have to be elected by the people (NGO Y).

The other two NGOs X and A had also expressed similar views about the legitimacy of the Hong Kong government. The issue of legitimacy of the government is clearly the core shared concern of the five NGOs because a fully representative government by universal franchise of the people is still not achieved though the Basic Law promised that Hong Kong will finally have a fully elected Chief Executive and Legislature Council. This lack of legitimacy and mandate from the people has seriously weakened the authority and credibility of the government.

\section{Autonomy}

This is not a commonly adopted criterion of good governance in many principles, or criteria suggested because unlike Hong Kong, most of the principles refer to a sovereignty state. Instead, as a special administrative region of PRC, Hong Kong has been granted high degree of autonomy, except on foreign and military affairs by the PRC government. Keeping this high degree of autonomy has always been considered as one of the crucial factors that keep Hong Kong successful. However, many Hong Kong people are worried of the gradual losing of the promised autonomy which will end up harming the future of Hong Kong as an open and free society. The worry was reflected in the interviews.

To judge on governance, we have to see whether the promise of 'One country, Two systems 'and high degree of autonomy, are being fully implemented. From many events, for example, in the political reform, or the issue of interpretation of Hong Kong laws by the National People's Congress of People's Republic of 
China (PRC), we found that the central government does not have the sincerity to implement fully the high degree of autonomy as promised (NGO X).

We can see that the two largest local political parties are both pro- establishment parties. In fact, they are not free from the influence of the PRC. From how they voted in the Legislative Council, it is clear that they were strongly influenced by the central government (NGO Z).

Though we have been guaranteed high degree of autonomy, except foreign and military affairs, our economic and social development is seriously influenced by the Guangdong Province government, which is backed up by the Central government (NGO B).

No one will challenge the Central government, that target is the people at the front of the stage... I would say this is a limitation of the "one country, two systems" approach. (NGO S)

\section{Check and Balance of Power}

There are many aspects of check and balance of power. We shall focus on the check and balance of power among the government, business sector and civil society. The representative from NGO A simply said:

The power is so imbalance that the business world, especially the property developers, gets the most, if not all, while the grass root people get so little, if not none.

The representative from NGO R said that this was one of the more practical and concrete aspects of an NGO's work:

Whereas political parties monitor the government and government departments- and when the performance is poor the parties will criticize or pressure the departments or ministers- I think NGOs can do this by being a critic of the entire system, rather than specific departments.

The representative from NGO Z elaborated further:

I think, ideally, there should be a balance of power among the government, business sector and civil society. However, the reality in capitalistic Hong Kong is that the greatest power lies with the business sector. The so called 'free market' is not so free. Instead it is dominated by several big business corporations. It is even worse that the government is seen to be siding with them to suppress the civil society. It is clear that the civil society has so little power in the whole process.

\section{Representatives of NGO X shared similar view:}

In the three sectors, government, business sector and civil society, the business sector is becoming more and more powerful, especially the property developers. Even the government is somehow powerless before them. The government is seen to be siding with the business sector to the degree that sometimes it is described as 'collusion between the government and the business sector'. The power of civil society is very limited.

Representatives of NGO Y shared similar view but with a more sympathetic attitude towards the government:

The government is seen to be becoming closer and closer to the business sector, like many capitalistic societies. This is not necessarily a deliberate act of the government. Instead, it reflects that the mode of economic development has become more monopolizing. In globalization, the big business becomes bigger and bigger while the smaller ones shrink. I think the government has always been close to the business sector. It is only the change of the environment that makes it appear to be becoming closer and closer.

Though the NGO people might have different interpretations of the role of the government, they all argued that the check and balance of power among the three sectors is distorted very much toward the business sector, making the grass root people suffer. The imbalance of Check and Balance of Power among the three sectors also reflects other characteristics of good governance, such as, Equity and Inclusion, Participation and Involvement of Civil Society, Accountability, but they will not be addressed in this paper.

\section{Characteristics of Good Governance: People's Factors}

Findings from this study suggest that, in addition to Institutional Factors, People's Factors are also important for Characteristics of Good Governance.

\section{Decision Makers}

During the interview with representatives of NGO X, the personal quality of the decision makers, which we refer as People's Factors Government Officers and Advisors was raised. However, the data also revealed that this human factor is severely constrained by the system:

Mr. $\mathrm{L}$ is now criticizing the Hong Kong government as he has left his official post from the government. He could not do this when he was in the post. I think the quality of decision makers is important but structural and institutional factors have great constraints on them (NGO X Rep 1) ${ }^{4}$.

Representative 2 of the same NGO echoed:

This view is important. Can those decision makers with a good conscience make something different? I believe we do have people with good conscience, but we do not have a good system that facilitates them.

The above views made by these two interviewees that personal factors are severely constrained by the structural factor, coincided with the findings by the SynergyNet that basically the crisis of governance the HKSAR faced originated from the structural and institutional factors and 
thus not from the people's factor - the personal quality of the decision makers [20]. It was clear that though the second HKSAR Chief Executive, Mr. Donald Tsang, with a stronger character than his predecessor Mr. Tung Chee Hwa, was an experienced civil servant for more than 30 years but the governance of the HKSAR was at the abyss at the end of his second term of office. Thus, it is plain and clear that the change of the chief executive could hardly solve the issue of weak government and poor governance for the HKSAR Government. Whether the Chief Executive has good conscience and wants to make his policy and administration beneficial to Hong Kong didn't seem decisive.

\section{Active Citizens}

From the literature above, active citizenry in the civil society is essential and crucial for good governance. Though after the return of sovereignty to PRC, Hong Kong society in general is becoming more politically active, the public awareness of their right to participate in public policy is still low [14-15]. Many of the citizens do not possess sufficient knowledge for democratic principles or intellectual and participatory skills necessary for competent participation in the democratic process. Even for those who are more aware of the right to participate, they tend to place own interests before common good of the whole society. Representative from NGO Z stated that the civic virtues of Hong Kong people were still very underdeveloped.

I discover that it seems that Hong Kong is still living in the old time. They think that they have to be ruled once they are born...Moreover, Hong Kong people are too individualized. They have no sense of social belonging. They only care about their own pocket - whether they can sell their flat, whether they can earn money. They never care about whether other citizens in the society have a place to live.

Interviewees from NGOs $\mathrm{A}, \mathrm{X}$ and $\mathrm{Y}$ have expressed similar views.

As the awareness and quality of political participation of Hong Kong citizens are still in an underdeveloped stage, it is important to explore whether the NGOs can contribute in raising the awareness of rights to participate of the Hong Kong citizens. Therefore, in the following discussion, we shall address research question 2: In what way(s) do NGOs perceive themselves as contributing to good governance through shaping of participatory political culture and acting as civic educator? We shall focus on the sub-themes, Community Education and Collaboration with Formal Education.

Overall speaking, all of them are involved in both community and school civic education in order to raise the awareness of the youth and the grass root people. However, they are basically advocacy NGOs and their top priority is promotion of issues of concern and influencing related policies. Though these two tasks are not necessarily separated, how much and in what ways they are involved in educational activities in practice depends much on the resources they could use for education. The tension between education and advocacy in term of resource is reflected from the interview of NGO Z:

In the past 12 years, we focused mainly on advocacy as our resources were very limited. But in these recent two years, we have paid more attention to educating the grass root people to be aware of their citizenship rights so as to consolidate the ground work of civil society.

\section{Community Education}

NGO Z continued to say that:

We want to organize, mobilize and sustain the grass root people through civic education. Through the education process, they reflect and become more and more aware of their rights and solidarity. Moreover, they are becoming trainers through the process. They will be invited to share with students in schools about their stories, poverty and the Comprehensive Social Security Assistant Scheme.

\section{Similarly NGO Y elaborated:}

We want the people to know that it is their basic rights to get help from the Comprehensive Social Security Assistant Scheme and it is not a charity from the government and they have the rights to participation. Also we want to enhance their awareness that poverty is a structural issue, not simply a personal issue. That is why we are actively involved in education for civil rights. But we find that to maintain their interest and concern is not easy.

For NGO A, since their aim is mainly on democratic development of HK, and their resources are very limited, they focus on education for political rights.

We educate the public to understand the meaning and importance of voting in democratic development of HK. We differ from the propaganda of the government that they emphasize on duty performance but we focus on the rights to participation, starting from voting to choosing of candidate and then move on to monitoring the candidates. However, it is difficult to sustain their interest.

For NGO X, they also carry out similar community education through the Christian church network while NGO B does less as it is more research oriented. Echoing CIVICUS (2006), in addition to advocating ideas and values, they are contributing to the quality of a vibrant civil society by raising civic awareness, particularly on the empowerment of rights awareness, and letting people's voices be heard. These are essential for good governance that can be achieved through community civic education. However, because of limited resources, there is tension between these two competing goals. Yet, their educational work does not stop at the community level but are getting more and more involved 
in school civic education.

Collaboration with Formal Education

Both NGO B and S are more involved at the tertiary education level. For NGO B, they are more research and academic oriented; they prefer to develop internship with tertiary institute, especially with teacher education institutes to train the trainers. NGO S similarly talked of their experiences giving talks at universities, particularly the Political / Public Administration departments to illustrate their vision of politics and how change will not come without struggle.

At secondary education level, though there are civic education programmes and activities in Hong Kong schools, advocacy NGOs, which are usually considered as radical, are seldom involved as schools in Hong Kong are in general conservative[21]. However, with the introduction of the mandatory subject, Liberal Studies (LS) in senior secondary level in September 2009, a platform for civic education was launched [21]. Since service learning and project learning have been proposed as learning and teaching strategies, the involvement of advocacy NGOs become possible [22-23].

One thing particular about NGO A is that it has members who are academics in political science in the local universities, who are interested in talking with secondary school students.

We have academics from the universities who go to schools to talk about issues related to democratization, usually in school assemblies before but more in LS lessons recently. We wish this kind of educational activities could somehow strengthen the civil society. But since our concern may not fit the LS syllabus, schools do not have a strong wish to invite us. It is the syllabus that determines the needs, and not the social development of the society nor the civic development of the students.

The representative of NGO Z shared his experience:

We had a project with schools. We invited trained grass root people receiving Comprehensive Social Security Assistant to share their living/ experience with the students. We want to introduce an alternative minority voice about Comprehensive Social Security Assistant against the major discourse, which label those receiving the scheme as lazy. We want to say that receiving welfare from the government is the basic right of a citizen. This is an enlightening process for three parties, the grass root people, students and even the teachers.

NGO X had done quite a lot of work with secondary schools.

We used to go to work with students in subjects like Integrated Humanity and Civic and Moral Education before. Now we are more involved in LS. But LS should not stay in the classroom. It has to go out to the community.

Using an example of experiential learning in a Poverty
Camp, NGO X elaborated:

The students were shocked when they talked and stayed with the farmers overnight. They listened to the farmers' inside stories during the struggle, which had not been disclosed. With this kind of human touch, we wish that their awareness can be enhanced. Our difficulties are how to sustain the interest of the schools. Sometimes they find that our concerns do not fit their syllabus, adding extra workload to them and not contributing to examination.

NGO R spoke of their school projects with LS students as having "less political ideology" instead of focusing on "enhancing the awareness of international relationships, national education, protection of environment, or art/culture related projects." For NGO Y, they recognize LS as a new opening for them. However, since their priority is community education, they remain passive in school civic education. However, though it seems that LS is a "golden opportunity" for advocacy NGO to get involved in formal education at the secondary level education, the worry that strongly advocacy oriented NGOs may lead to biased messages and indoctrination have been expressed by teachers [23]. How the collaboration between schools and NGOs could address the tension between education and advocacy is a crucial issue for further research and exploration.

In short, the interviewees of the 7 NGOs all agreed that apart from contributing towards the enhancement of various characteristics of good governance in Hong Kong, such as: legitimacy and power, participation and involvement of civil society, accountability, the rule of law, transparency, responsiveness, consensus oriented, equity and inclusiveness, political stability and absence of violence, and regulatory quality; NGOs played a crucial role in helping the government to gauge the views of the stakeholders within the society and pacified those discontented through direct and indirect support and services to them. NGOs have done a great job to fulfill part of the government's responsibility in redressing people's grievances and demands on social welfare sectors. Thus, the interviewees unanimously agreed that without the support from the NGOs in Hong Kong, particularly NGOs' provision of various kinds of services to the people of Hong Kong, the government is unlikely to be regarded as gearing at good governance.

\section{The Occupy Central Movement in Hong Kong and Its Aftermath}

The Occupy Central or Umbrella Revolution is a series of mass sit-in street protests that occurred in Hong Kong from 26 September to 15 December 2014. Thousands of protesters blocked roads and paralysed Hong Kong's business and financial areas. They demanded the Beijing and Hong Kong governments to implement universal suffrage for the chief 
executive election in 2017 and the Legislative Council elections in 2020 according to "international standards." Completely different from other political movements in Hong Kong, the Occupy Central movement was not initiated by political parties, but by academics from the universities, NGOs and students' organizations such as Scholarism and students unions of the universities in general. The movement received massive support from the population of Hong Kong, especially the younger generation. The fact that our interviewees $\mathrm{A}, \mathrm{X}$ and $\mathrm{Y}$ remarked that the awareness and quality of political participation of Hong Kong citizens were at the rudimentary stage, why did these passive citizens suddenly became active and eager to participate in politics? Would it be fair to say that NGOs played a crucial role in raising people's awareness of their citizenship right and thus the demand for universal suffrage on the chief executive and Legislative Council elections according to international standard? The Occupy Central movement was later renamed to be the "Umbrella Movement" by the media worldwide because students used umbrella to protect themselves from the tear gas administered on them during their confrontation with the police in Hong Kong. The Movement was called off after a few months' occupation of the financial districts. Yet, the seeds of the demand for more democracy and universal suffrage had been shown. It is without doubt that the people of Hong Kong, especially the NGOs and the younger generation, became more politicized since then.

\section{The District Council Election on November 22, 2015}

The District Council Election on November 22, 2015 became the barometer to test the people of Hong Kong and voters' sentiment in the post-Occupy period.

The election marked the highest turnout and turnout rate since the handover at 1.47 million and 47 percent respectively. The result of the election was as follows:

\begin{tabular}{|c|c|c|}
\hline Party & Seats won & 2011 Election \\
\hline DBA & 119 & 119 \\
\hline Democratic Party & 43 & 47 \\
\hline Federation of Trade Unions & 29 & 29 \\
\hline New people's party/Civil Force & 26 & Not merged then \\
\hline ADPL & 18 & 15 \\
\hline Neo Democrats & 15 & 8 \\
\hline Business and professionals & 10 & Not founded yet \\
\hline Alliance & 10 & 7 \\
\hline Civic Party & 9 & 9 \\
\hline Liberal Party & 9 & Not founded yet \\
\hline Umbrella Soldiers & 3 & Not founded yet \\
\hline Labour Party &
\end{tabular}

It was astonished that neither the pro-establishment camp nor its mainstream opposition were able to turn the high turnout in their favor. The pro-government camp still able to retain control of the 18 district councils though lost a few seats overall. Three pan-democrats' heavyweights suffered a setback in the election. Most of the seats lost by the two great camps were given to a new generation of activists. The result of the election confirmed the pre-election prediction by some academics and political commentators that voters have become more polarized since the Occupy Central movement. The Neo Democrats- the "pragmatic localism" party, strike a perfect score as 15 out of 16 candidates won their seats in the election, a success rate of nearly 94 percent. The party attributed its success to their community work, the positive impact of the Umbrella Movement and the party's pragmatic localism appealed to the voters. The People Power suffered their Waterloo at the election as only one candidate was able to secure a seat in the district council while 8 other candidates lost. Given that this is the plight of the existing political arena, would it be true and fair to say that the era of forceful political tactics comes to an end? The success of the new generation Occupy activists with the endorsement of the first-time voters in the election clearly shows that the younger generation wants to change those political areas which the authorities want to preserve their status quo. The recent election has also clearly pointed out that political affiliation might not be an advantage as an elected NGO leader affirmed that "Some people view parties negatively." Thus, it is not suprising that the new generation Occupy activists attributed their success in the election to their community work, people's hope for change and NGOs which provided the fertile ground to nurture the new political generation.

\section{Conclusions}

This study with NGOs points out that there is a shared belief among NGOs about their potential contribution to the building up of good governance in Hong Kong. The NGO's conception of good governance in the Hong Kong context, as revealed by data obtained in this study, comprises inter alia: legitimacy obtained through democratic elections, ability to realize the autonomy of the HKSAR, and proper checks and balances not just within the government but also about the possible domination of business interest in the government's policy making process. This reflects the worldwide criteria of good governance in the first place and the uniqueness of Hong Kong as a special administrative region with a high degree of autonomy on the other, particularly the building up of a truly democratic government is yet to be realized.

The NGOs interviewees commented quite negatively about the current status of governance in Hong Kong, though at least one NGO still sympathized with the government on its poor performance in governance due to its inability to revert the balance in the check and balance of power among the government, business sector and civil society. Whilst we need to admit the choice of NGOs may be a reason for this, we should not overlook the possibility that the plight of the underprivileged may have worsened particularly that the gap 
between the rich and the poor has been increasing. This widening wealth gap may disappoint the NGOs we interviewed particularly given that most of them are serving the poor and the marginalized groups. It is interesting to note on the other hand that from the discourses of some NGO leaders we interviewed, they believed that the widening gap between the rich and the poor and the lack of a truly democratic government are intertwined. The importance of business interest in the functional constituencies of the Legislative Council and the conservative attitude of some members returned by functional constituencies in legislation over people's livelihood etc. can be important behind such a belief. However limited the number of samples the researchers interviewed, there is a general congruency on NGOs' views on HKSAR Government's poor performance in governance. In fact, the samples represented more than $5 \%$ of the total working population in the field, and their views in one way or the other represented NGOs impression on the HKSAR government and governance in Hong Kong. Judging from the above mentioned reasons, the researchers therefore confirmed that the occurrence of this belief within the NGOs was largely due to the disparity between the rich and the poor within the society on the one hand, and the inability of the government to solve the problems of the poor and ease the tensions within the territory on the other.

Hong Kong is now on the edge of 'torn between two partners' on the demand for the right to choose the next Chief Executive through universal suffrage in 2017. The pan-democrats planned to Occupy Central given that their demand is not acceded. They launched a mock universal suffrage on $22^{\text {nd }}$ June, 2014 and the number of participants was 800,000 . According to the organizer's estimation, there were also over 510,000 people participated in the July 1, 2014 demonstration to demand the HKSAR to redress their grievances and the universal suffrage. The Pro-establishment camps, led by the Alliance for Peace and Democracy, also initiated an "anti-violence, anti-Occupy Central, protect peace, protect democracy" Rally on $17^{\text {th }}$ August, 2014. They claimed that there were nearly 200,000 people participated in the March, the largest pro-government rally seen in Hong Kong. The Pro-establishment Camps also launched a mock universal suffrage to support the 2017 chief executive election in accordance to the Basic Law and opposed all unlawful acts which affect social order and the betterment of the people of Hong Kong. According to the Alliance for Peace and Democracy estimation, the total number of voters in the event was 1.5 million. Admittedly, both sides have their views on what they regarded as 'universal suffrage' and the 'rule of law'. It is good to see that people of Hong Kong is now away from their 'political apathetic' and more willing to participate in politics. Neither is it an easy job to calculate to what extent is the present change contributed by advocacy NGOs. Nor is it an easy task to find out the role of NGOs in governance through cultivating of a participatory culture. However, it is undeniable to say that there exists a participatory culture in Hong Kong and NGOs have laid the mile stone for it.

It is clear from the above discussion that all the seven NGOs recognized that cultivating a vibrant civil society with active, participatory citizens, through community or school civic education, is a significant contribution to many characteristics of good governance and they are actively involved in different capacities. However, a commonly shared difficulty for them is the maintenance of interest of the people, no matter they are teacher, students, or grass root citizens, on good governance.

NGO's possible contribution to civic education is an interesting topic to explore. The discussion of NGOs as agents of political socialization has gradually emerged in literature as the importance accorded to civil society in the building up of democracy has increased [21, 23-25]. Mercier [26] explained that NGOs are increasingly involving themselves in discussion about civil society, democracy, good governance and social capital, although often from a Western perspective. Cross and Young [27] extending work by Inglehart [28] and Nevitte [29] indicated that advocacy groups might have superseded political parties in appealing to youths. This point of view can be confirmed by the success of the recent anti-brain wash national education advocacy group that helped to rally a great number of supporters at the Central Government Office to urge the HKSAR Government to put a stop on the incorporation of National Education into the Hong Kong school curriculum in September 2012. In this particular case, the leaders of the movement were largely the advocacy groups, and the role between the political parties vis-à-vis the advocacy groups has turned upside down. The increasing in importance of the NGO advocacy groups in the Hong Kong political arena prompted the researchers to argue that the people's factor may help to explain the fact that the NGO advocacy groups can influence the administration and policy formulation of the HKSAR. A worldwide awareness and coincidence to this view was that there were many scholars argued for NGOs' assuming a civic education mission in the past decade. Abom [30] pointed out that since 1980s more NGOs have become involved in advocacy, lobbying and civic education. Leung [23] considered NGOs as agents of civic education that can help students to reconstruct meaning over social issues. Also, the Occupy Central Movement from 26 September to 15 December 2014 and its aftermath until then vividly affirmed this. The Council of Europe has recently made a strong claim that NGOs are important in civic education for democratic citizenship. They can lobby governments in order to influence formal education at all levels, then work directly to educate people in the democratic life. [31] Notwithstanding these studies, how NGOs could provide civic education programs with impartiality, regardless of their strong orientation and the impact such works could bring is still a matter where research is needed. 


\section{REFERENCES}

[1] Stoker, G., Governance as theory: Five propositions, Blackwell, International Social Sciences Journal, Vol.50 No.1, 17-28, 1998 .

[2] Kooiman, J. \& Vliet, M. V., Managing public organizations: Lessons from contemporary European experience, Governance and public management. In K. A. Eliassen \& J. Kooiman (Eds.), London, England: Sage Publications, 1993.

[3] Kooiman, J., Modern governance: New government-society interactions, In J. Kooiman (Ed.), Governance and governability: Using complexity, dynamics and diversity. London, England: Sage Publications, 1993.

[4] Centre for Governance and Citizenship, Proposal to set up a new Institute-level Research Centre dedicated to the Scholarship of Governance and Citizenship Studies, Unpublished. 2009.

[5] Kaufmann, D., Kraay, A. \& Mastruzzi, M., The worldwide governance indicators: Methodology and analytical issues [Internet]. World Bank Policy Research Working Paper 5430; [2010]. Available from http://papers.ssrn.com/sol3/papers.cf m?abstract_id $=1682130$.

[6] The Commission of the European Communities, European governance: A white paper, Brussels, Belgium: Author, 2001.

[7] What is good governance? [Internet] [place unknown]; United Nation Economic and Social Committee on Asia and Pacific (UNESCAP).[date unknown] Available from http://www.unescap.org/sites/default/files/good-governance. pdf.

[8] Cheema, G. S., Civil society engagement and democratic governance: An introduction, In G. S. Cheema and V. Popovski (Eds.), Engaging civil society: Emerging trends in democratic governance, Tokyo and New York: United Nations University Press, 2010.

[9] Commonwealth of Australia, Good governance: Guiding principles for implementation, Canberra, Australia: Australian Agency for International Development, 2000.

[10] Edwards, M., Civil society, (2 ${ }^{\text {nd }}$ ed.), Cambridge, England: Polity Press, 2009.

[11] Hann, C. \& Dunn, E., (Eds.), Civil society: Challenging Western models, London and New York: Routledge, 1996.

[12] White, G., Civil society, democratization and development: Clearing the analytical ground, Routledge Taylor \& Francis Group, Democratization, Vol.1 No.3, 375-390, 1994

[13] Civil Society Index Report: Hong Kong Administrative Region, The People's Republic of China [Internet]. CIVICUS [2006]. Available from http://web.hku.hk/ ccsg/files/CSI\%20report\%202006.pdf.

[14] Fairbrother, G., Power and right in Hong Kong's citizenship education, Cambridge, MA, Citizenship Studies, Vol.9 No.3, 293-308. 2005.

[15] Ghai, Y. , Citizenship and Politics in the HKSAR: the constitutional framework, Cambridge, MA, Citizenship Studies, Vol.5 No.2, 143-164. 2001.

[16] Leung, Y.W. \& Yuen, W.W., Creating socially responsible citizens: Cases from Asian-Pacific Region, In J. Cogan \& D. Grossman (Eds.), The Development of Civic and Moral Education in Hong Kong's Changing Context, Charlotte: Information Age Publisher, 2012, p.35-67.

[17] NGO Handbook 2014 [Internet][date unknown]. Available from: http://www.ngohandbook.org

[18] HKSAR Census \& Statistics Department (2013), Hong Kong Statistics 2013

[19] Glaser, B. \& Strauss, A., The discovery of grounded theory, New York, NY: Aldine Gruyter, 1967.

[20] Report on the Assessment on the Governance of the HKSAR, pp. 33-34. [Internet]. Hong Kong; SynergyNet; 2010 [cited December, 2010]. Available from: www.synergynet.org.hk

[21] Leung, Y.W. \& Yuen, W.W., Participatory citizenship and student empowerment: Case study of a Hong Kong school, Citizenship Teaching and Learning, Vol.5 No.1, 18-34, 2009.

[22] Leung, Y.W., Citizenship education through service learning: From charity to social justice, The Chinese University of Hong Kong. Educational Journal, Vol.31 No.1, 95- 117, 2003.

[23] Leung, Y.W., How do they become socially/ politically active? : Case studies of political socialization of Hong Kong secondary students, Citizenship Teaching and Learning, Vol.2 No.2, 51-67, 2006.

[24] Tocqueville (de), A. (1981 [1835]) De la Democratie en Amerique. Paris: Garnier-Flammarion.

[25] Putnam, R. Leonardi, R. \& Nanetti, R.,Making democracy work: Civic tradition in modern Italy, Princeton, NJ: Princeton University Press, 1993.

[26] Mercier, C., NGOs, civil society and democratization: A critical review of the literature, Sega, Progress in Development Studies, Vol.2 No.1, 5-22, 2002.

[27] Cross, W. \& Young, L., Factors influencing the decision of the young politically engaged to join a political party: An investigation of the Canadian case, Sega, Party Politics, Vol.14 No. 3, 345-369. 2008.

[28] Inglehart, R., Culture shift in advanced industrial society, Princeton, N.J.: Princeton University Press, 1990.

[29] Nevitte, N.,The decline of deference: Canadian value change in cross-national perspective, Peterborough, ON: Broadview Press, 1996.

[30] Abom, B., Social capital, NGOs, and development: A Guatemalan case study, Oxford : Oxfam UK and Ireland, Development in Practice, Vol.14, No.3, 342-353, 2004.

[31] Council of Europe [Internet][date unknown]. Available from: http://www.coe.int/. 